\title{
Study of Serum Hepcidin Level and its Relation to Recombinant Human Erythropoietin Resistance, Markers of Iron Status and C-reactive Protein in Patients with End Stage Renal Disease on Maintenance Haemodialysis
}

\author{
Ayman M. Elbadawy, W. M. Ibraheim, Medhat A. Khalil, Omar N. Elhawary, Rasha O. Abdelmoniem
}

\begin{abstract}
Department of internal medicine, Benha faculty of medicine, Banha University, Egypt.

Correspondence to: Omar N. El-Hawary, Department of internal medicine, Benha faculty of medicine, Banha University, Egypt
\end{abstract}

Email:

omarelhawary1990@gmail.com

Received: 6 March 2021

Accepted: 3 April 2021
Abstract

Background: Anemia represents a significant problem to deal with in patients with chronic kidney disease (CKD) on haemodialysis (HD). This work aimed to determine the usefulness of measuring serum hepcidin level in patients with end stage renal disease (ESRD) on maintenance hemodialysis and anemia, and assess the possible correlation between serum hepcidin level and markers of iron status (serum iron, serum ferritin, total iron binding capacity and iron saturation), erythropoietin resistance and inflammatory markers (C-reactive protein). Methods: The study was performed on (50 patients) with end stage renal disease on maintenance haemodialysis. Patients were divided into two groups: group (I): 40 patients who have anaemia responsive to erythropoietin therapy and group (II): 10 patients who have anaemia resistant to erythropoietin therapy. All patients were subjected to thorough history taking, clinical examination, and laboratory investigations. Results: serum hepcidin level was higher in all patients with erythropoietin resistance index $(\mathrm{ERI})<15$ compared to patients

with ERI > 15. There was a highly significant positive correlation between serum hepcidin level and ERI and significant negative correlation between serum hepcidin level and serum iron, ferritin and transferrin saturation. But no significant correlation between serum hepcidin level and C-reactive protein. Conclusion: Hepcidin is associated with anemia, markers of iron status and erythropoietin resistance. If used as a diagnostic tool, it might improve iron therapy in patients with functional iron deficiency due to reticuloendothelial blockage of iron transport. This is important to avoid iron overload and to improve erythropoietin (EPO) response in patients with ESRD.

Keywords: Hepcidin; Erythropoietin resistance; Markers of iron status; Inflammatory markers. 


\section{Introduction}

Chronic kidney disease (CKD) is defined as the presence of kidney damage or an estimated glomerular filtration rate (eGFR) less than 60 $\mathrm{ml} / \mathrm{min} / 1.73 \mathrm{mt} 2$, persisting for 3 months or more, irrespective of the cause. It is a state of progressive loss of kidney function ultimately resulting in the need for renal replacement therapy (dialysis or transplantation). (1)

Anaemia is a common comorbidity associated with chronic kidney disease (CKD); it starts early in the course of the disease and worsens as renal function declines. Anaemia associated with declining kidney function is predominantly due to inadequate renal production of the hormone erythropoietin in response to low haemoglobin ( $\mathrm{Hb})$ levels. As kidney function worsens, erythropoietin production decreases, resulting in the frequent comorbidity of anaemia with CKD. (2)

Hepcidin, an endogenous peptide secreted by the liver, has been identified as controlling the level of plasma iron by regulating the intestinal absorption of dietary iron, as well as the release of iron from macrophages and the transfer of iron stored in the hepatocytes. Hepcidin production is suppressed in the case of iron deficiency; the feedback loop between iron and hepcidin should ensure the appropriate physiological concentration of iron in the plasma. Hepcidin suppression causes the stored iron to be released by hepatocytes and macrophages while the intestinal absorption of iron increases (3).

Hepcidin is elevated during inflammation and/or infection. This can cause iron dysregulation with hypoferremia and anaemia related to inflammatory disease. Hypoferremia can also represent a strategic host defence to limit iron availability to microorganisms. Kidney function (i.e., excretion) plays an important role in hepcidin clearance. Patients with end stage renal disease on maintenance hemodialysis have decreased levels of hepcidin clearance and hepcidin level increases regardless of the inflammatory state. (4)

This study aimed to determine the usefulness of measuring serum hepcidin level in patients with end stage renal disease on maintenance hemodialysis and anemia, and to assess the possible correlation between serum hepcidin level and markers of iron status (serum iron, serum ferritin, TIBC and iron saturation), erythropoietin resistance, and inflammatory markers as CRP. 


\section{Patients and methods}

This cross-sectional study was conducted on 50

patients attending the Dialysis unit at Benha health insurance hospital during the period from January 2020 to January 2021.

This study was approved by the Ethical Committee of Benha Faculty of Medicine, a written consent was taken from all subjects before enrolment of the study.

The study was performed on (50 patients) with end stage renal disease on maintenance haemodialysis. Patients were divided into two groups: group (I): 40 patients who have anaemia responsive to erythropoietin therapy and group (II): 10 patients who have anaemia resistant to erythropoietin therapy.

All patients had been informed about the purpose of the study and signed consent before inclusion.

Inclusion criteria:

1. patients with end stage renal disease (ESRD) on maintenance hemodialysis, with good patient compliance and less missed treatments.

2. Age $18-75$ years old.
3. Patients receiving recombinant erythropoietin therapy for at least 8 week for treatment of anaemia.

Patients who fulfilled the inclusion criteria were on regular dialysis three sessions per week, $4 \mathrm{~h}$ for each session using 'Fresenius 4008S Classic' dialysis machine at blood flow rate of $300-350 \mathrm{ml} / \mathrm{min}$, dialysate flow rate of $600 \mathrm{ml} / \mathrm{min}$, using high flux polysulfone hollow fiber dialyzers suitable for the surface area of the patients (Fresenius FX8=1.4 m2, $\mathrm{FX} 10=1.8 \mathrm{~m} 2$ and $\mathrm{F} 6=1.2 \mathrm{~m} 2$ ) with adequate dialysis treatment $(\mathrm{Kt} / \mathrm{V}>1.4)$ in more than $80 \%$ of the patients.

Exclusion criteria:

Patients were excluded from the study if they had :

- Uncontrolled hypertension or diabetes.

- Liver dysfunction.

- Malignancy.

- Haemoglobinopathies.

- Hepatitis C or Hepatitis B virus.

- Active or subclinical infection.

- Blood transfusion within the past 3 months.

- Patients treated with steroids or other immunosuppressive drugs are also excluded from the study. 
All patients were subjected to thorough history taking, clinical examination, and laboratory investigations as complete blood count (CBC), serum hepcidin level, markers of iron status (Serum iron, serum ferritin, total iron binding capacity, and transferrin saturation), C-reactive protein (CRP), serum parathormone hormone level (PTH), total and ionized calcium $(\mathrm{Ca}++)$, serum phosphorus (Po4-), serum creatinine, blood urea, hepatitis B surface antigen (HBsAg) and hepatitis C antibody.

The erythropoietin resistance index (ERI) was calculated as the weekly dose of EPO (IU/kg/week) divided by haemoglobin concentration $(\mathrm{g} / \mathrm{dl})$ multiplied by the dry body weight $(\mathrm{Kg})$ of each patient (where the dry weight was the post dialysis body weight averaged across 3 dialysis sessions at the end of the outcome period).

Serum hepcidin was measured using enzymelinked immunosorbent assay. The assay was carried out by hepcidin enzyme-linked immunosorbent assay kits.

Statistical analysis:

The collected data were tabulated and analyzed using SPSS version 16 software (SpssInc, Chicago, ILL Company). Categorical data were presented as number and percentages, Fisher's exact tests was used to analyze them.
Quantitative data were tested for normality using Shapiro -Wilks test assuming normality at $\mathrm{P}>0.05$. Normally distributed variables were expressed as mean \pm standard deviation, median was added if non parametric. Student " $t$ " test was used to analyze the difference between 2 independent groups regarding parametric variables, while non parametric ones were analyzed by Mann Whitney $U$ test (ZMWU). Correlation was assessed by the non-parametric correlation coefficient Spearman (rho).

Multiple linear regression analysis was run to detect the predictors of Hepcidin and ERI. ROC curve was constructed to determine a cutoff value of Hepcidin and assess its performance in prediction of erythropoietin resistance among dialysis patients. $\mathrm{P} \leq 0.05$ was considered significant.

\section{Results}

Patients had an age range between 18 and 75 years old with a mean of $52.3 \pm 14.5$ years. Regarding sex of the patients, 41 patients (82 $\%)$ were males and $9(18 \%)$ were females. The mean body mass index (BMI) was 27.4 \pm 3.7 $\mathrm{kg} / \mathrm{m} 2$. (Table 1)

We divided our patients into EPO sensitive and EPO resistant groups according to the erythropoietin resistant index (ERI). We found 
that $80 \%$ of patients were EPO sensitive (40 patients) with ERI > 15 and $20 \%$ were EPO resistant (10 patients) with EPO $<15$. (Figure 1)

(Table 2) shows the comparison between the EPO sensitive patients and the EPO resistant patients according to different laboratory results. There was statistically significant difference between groups regarding serum hepcidin level, $\mathrm{Hb}$, iron, TIBC, ferritin, and transferrin saturation. Whereas there was no statistically significant difference between groups regarding mean CRP level, PTH, total calcium, or phosphorus.

(Table 3) shows the correlation between serum hepcidin level and different variables. There was a significant positive correlation between hepcidin and (ESA/w, TIBC, phosphorus, and ERI), and a significant negative correlation between hepcidin and ( $\mathrm{Hb}$ level, iron level, ferritin, and T. saturation). No significant correlation between hepcidin and (age, weight, BMI, CRP titre, PTH, or serum $\mathrm{Ca}++$ ) was found.

(Table 4) shows Correlation between erythropoietin resistance index and the studied variables. There was a significant positive correlation between ERI and (ESA/w, TIBC, and hepcidin level), and a significant negative correlation between ERI and ( $\mathrm{Hb}$ level, iron level, ferretin, and transferrin saturation). While there was no significant correlation between ERI and (age, weight, BMI, CRP, $\mathrm{PTH}$, total $\mathrm{Ca}$, or phosphorus).

Table (1): Socio-demographic data of the studied group:

\begin{tabular}{|c|c|c|c|}
\hline Variable & & & No. $(\mathrm{N}=50)$ \\
\hline \multirow[t]{2}{*}{ Age (years) } & Mean \pm SD & & $52.3 \pm 14.5$ \\
\hline & Median (Range) & & $57(20-74)$ \\
\hline \multirow[t]{2}{*}{$\operatorname{Sex}(n \%)$} & Male & 41 & 82.0 \\
\hline & Female & 9 & 18.0 \\
\hline Weight (kg) & Mean \pm SD & & $79.8 \pm 13.5$ \\
\hline \multirow{3}{*}{ BMI $\left(\mathrm{kg} / \mathrm{m}^{2}\right)$} & Median (Range) & & $81(61-120)$ \\
\hline & Mean \pm SD & & $27.4 \pm 3.7$ \\
\hline & Median (Range) & & $27.3(19.4-37)$ \\
\hline
\end{tabular}

BMI: body mass index. 
Table (2): Comparison between EPO sensitive and resistant patients regarding different laboratory parameters:

\begin{tabular}{|c|c|c|c|c|c|c|c|c|}
\hline \multirow[t]{2}{*}{ Variable } & \multicolumn{3}{|c|}{$\begin{array}{l}\text { Erythropoietin sensitive } \\
\qquad(\mathrm{n}=40)\end{array}$} & \multicolumn{3}{|c|}{$\begin{array}{l}\text { Erythropoietin resistant } \\
\qquad(\mathrm{n}=10)\end{array}$} & \multirow{3}{*}{$\begin{array}{c}\mathrm{Z}_{\mathrm{MWU}} \\
2.87\end{array}$} & \multirow{3}{*}{$\begin{array}{c}\mathrm{P} \\
0.004(\mathrm{~S})\end{array}$} \\
\hline & Mean & $\pm \mathrm{SD}$ & Median (Range) & Mean & $\pm \mathrm{SD}$ & Median (Range) & & \\
\hline $\mathrm{Hb}(\mathrm{g} / \mathrm{dl})$ & 11.0 & 0.84 & $11.1(9.2-12.2)$ & 10.1 & 0.65 & $\begin{array}{c}10.3 \\
(9.4-11)\end{array}$ & & \\
\hline Serum iron (ug/dl) & 74.8 & 28.6 & $\begin{array}{c}66.0 \\
(37-146)\end{array}$ & 62.6 & 20.0 & $\begin{array}{c}49.0 \\
(17-85)\end{array}$ & 2.55 & $0.011(\mathrm{~S})$ \\
\hline TIBC (ug/dl) & 257.6 & 39.1 & $\begin{array}{c}258.0 \\
(208-338)\end{array}$ & 316.0 & 91.2 & $\begin{array}{c}272.0 \\
(269-489)\end{array}$ & 2.16 & $0.031(\mathrm{~S})$ \\
\hline $\begin{array}{l}\text { Serum ferritin } \\
(\mathrm{ng} / \mathrm{ml})\end{array}$ & 648.5 & 633.9 & $\begin{array}{c}627.0 \\
(49-3055)\end{array}$ & 305.5 & 211.1 & $\begin{array}{c}207.5 \\
(129-647)\end{array}$ & 2.43 & $0.015(\mathrm{~S})$ \\
\hline $\begin{array}{l}\text { Transferrin } \\
\text { saturation (\%) }\end{array}$ & 28.4 & 11.90 & $\begin{array}{c}24.9 \\
(7.6-53)\end{array}$ & 19.7 & 8.58 & $\begin{array}{c}18.0 \\
(10-31.6)\end{array}$ & 2.1 & $0.036(\mathrm{~S})$ \\
\hline $\begin{array}{l}\text { Serum } \\
(\mathrm{pg} / \mathrm{ml})\end{array}$ & 456.7 & 330.4 & $\begin{array}{c}353.0 \\
(24-1062)\end{array}$ & 422.6 & 288.2 & $\begin{array}{c}312.0 \\
(213-960)\end{array}$ & 0.097 & $0.92(\mathrm{NS})$ \\
\hline Total ca (mg/dl) & 8.47 & 0.90 & $\begin{array}{c}8.8 \\
(7.2-10.3)\end{array}$ & 8.66 & 0.58 & $\begin{array}{c}8.6 \\
(7.9-9.6)\end{array}$ & 0.27 & $0.78(\mathrm{NS})$ \\
\hline $\begin{array}{l}\text { Serum phosphorus } \\
(\mathrm{mg} / \mathrm{dl})\end{array}$ & 5.64 & 1.34 & $\begin{array}{c}5.7 \\
(2.5-8.3)\end{array}$ & 5.90 & 1.25 & $\begin{array}{c}5.9 \\
(4.3-7.5)\end{array}$ & 0.53 & $0.59(\mathrm{NS})$ \\
\hline $\begin{array}{l}\text { Serum hepcidin } \\
(\mathrm{ng} / \mathrm{ml})\end{array}$ & 736.3 & 603.3 & $\begin{array}{c}462.3 \\
(29.8-1780)\end{array}$ & 1298.1 & 598.1 & $\begin{array}{c}1632.0 \\
(203.3-1782)\end{array}$ & 2.24 & $0.025(\mathrm{~S})$ \\
\hline CRP titer (mg/L) & 29.6 & 25.5 & $\begin{array}{c}20 \\
(6-96)\end{array}$ & 32.2 & 31 & $\begin{array}{c}24 \\
(6-96)\end{array}$ & 0.18 & $\begin{array}{l}0.85 \\
(\mathrm{NS})\end{array}$ \\
\hline
\end{tabular}

Hb: hemoglobin; TIBC: Total Iron Binding Capacity; PTH: Serum Parathormone hormone level; Ca: Calcium $(\mathrm{Ca}++)$ 
Table (3): Correlation between serum hepcidin level and different variables :

\begin{tabular}{|c|c|c|}
\hline \multirow[t]{2}{*}{ With } & \multicolumn{2}{|c|}{$\begin{array}{c}\text { Hepcidin }(\mathrm{ng} / \mathrm{ml}) \\
\text { Dialysis patients } \\
\quad(\mathrm{N}=\mathbf{5 0})\end{array}$} \\
\hline & rho & $\mathbf{P}$ \\
\hline Age (ys) & 0.017 & 0.91 \\
\hline Weight (Kg) & 0.033 & 0.82 \\
\hline BMI (Kg/m2) & 0.223 & 0.11 \\
\hline $\mathrm{ESA} / \mathrm{w}$ & 0.504 & $<0.001(\mathrm{HS})$ \\
\hline $\mathrm{Hb}(\mathrm{g} / \mathrm{dl})$ & -0.328 & $0.02(\mathrm{~S})$ \\
\hline CRP titre $(\mathrm{mg} / \mathrm{L})(\mathrm{n}=32)$ & 0.279 & 0.12 \\
\hline Iron $(\mathrm{mg} / \mathrm{dl})$ & -0.394 & $0.005(\mathrm{~S})$ \\
\hline TIBC (mg/dl) & 0.280 & $0.049(\mathrm{~S})$ \\
\hline Ferritin (ng/ml) & -0.300 & $0.034(\mathrm{~S})$ \\
\hline Transferrin saturation (\%) & -0.380 & $0.006(\mathrm{~S})$ \\
\hline PTH (pg/ml) & 0.158 & 0.27 \\
\hline Total ca $(\mathrm{mg} / \mathrm{dl})$ & 0.01 & 0.95 \\
\hline Phosphorus (mg/dl) & 0.407 & $0.003(\mathrm{~S})$ \\
\hline ERI & 0.462 & $=0.001(\mathrm{HS})$ \\
\hline
\end{tabular}

ESA: erythropoiesis-stimulating agents; BMI: body mass index; CRP: C-reactive protein; Hb: hemoglobin; TIBC: Total Iron Binding Capacity; PTH: Serum Parathormone hormone level; Ca: Calcium $(\mathrm{Ca}++)$; ERI: Erythropoietin resistant index

Table (4): Correlation between erythropoietin resistance index and the studied variables :

\begin{tabular}{|c|c|c|}
\hline \multirow[t]{2}{*}{ With } & \multicolumn{2}{|c|}{$\begin{array}{c}\text { ERI } \\
\text { Dialysis patients } \\
(\mathrm{N}=\mathbf{5 0}) \\
\end{array}$} \\
\hline & rho & $\mathbf{P}$ \\
\hline Age (ys) & 0.076 & 0.59 \\
\hline Weight (Kg) & 0.193 & 0.18 \\
\hline BMI (Kg/m2) & 0.269 & 0.059 \\
\hline ESA/ w & 0.907 & $<0.001(\mathrm{HS})$ \\
\hline $\mathrm{Hb}(\mathrm{g} / \mathrm{dl})$ & -0.570 & $<0.001(\mathrm{HS})$ \\
\hline CRP titre $(\mathrm{mg} / \mathrm{L})(\mathrm{n}=32)$ & 0.064 & 0.73 \\
\hline Iron $(\mathrm{mg} / \mathrm{dl})$ & -0.415 & $0.003(\mathrm{~S})$ \\
\hline TIBC (mg/dl) & 0.331 & $0.019(\mathrm{~S})$ \\
\hline Ferritin (ng/ml) & -0.441 & $=0.001(\mathrm{HS})$ \\
\hline Transferrin saturation (\%) & -0.466 & $=0.001(\mathrm{HS})$ \\
\hline PTH $(\mathrm{pg} / \mathrm{ml})$ & 0.128 & 0.37 \\
\hline Total ca (mg/dl) & -0.190 & 0.18 \\
\hline Phosphorus (mg/dl) & 0.215 & 0.13 \\
\hline Hepcidin (ng/ml) & 0.462 & $=0.001(\mathrm{HS})$ \\
\hline
\end{tabular}




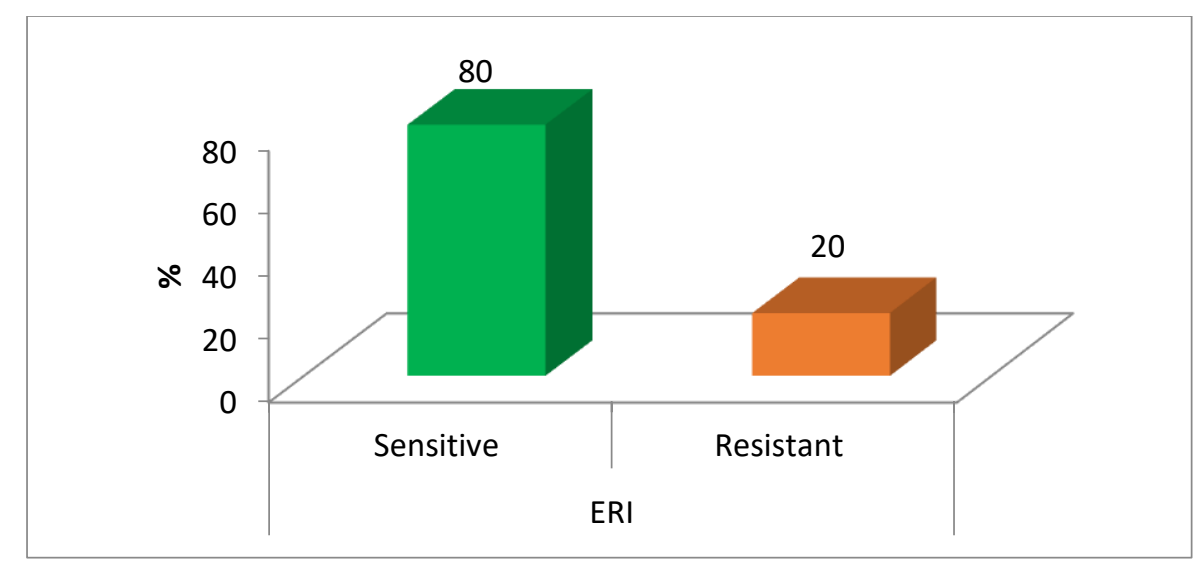

(Fig 1): Bar chart showing the frequency of EPO resistance among the studied sample.

\section{Discussion}

We found that there is a highly significant positive correlation between serum hepcidin level and ERI among our hemodialysis patients . This correlation is due to the effect of hepcidin on iron as hepcidin decreases available iron and hence decreases erythropoiesis and hemoglobin concentration, so that patients with decreased hemoglobin will get higher doses of EPO per week.

According to the equation of ERI, ERI is directly proportional to the weekly doses of EPO but inversely proportional to mean hemoglobin level so higher hepcidin will lead to more high ERI and this can explain our study results and also in agreement with another study results. (5)

However, other authors present opposite results. For example in two studies (6) and (7) it was found that hepcidin serum levels among EPO resistant group (ERI > 15) were significantly lower than among EPO sensitive group $($ ERI $<15)$.

As EPO resistant group present with higher inflammatory markers, hepcidin levels are expected to be increased, but it has been demonstrated that erythropoietin downregulates liver hepcidin expression, acting, therefore, as a hepcidin inhibitory hormone. Since EPO resistant group were treated with much higher doses of erythropoietin compared with EPO sensitive group, the lower hepcidin levels among EPO resistant group could be explained by this mechanism.

In our study, we found that $\mathrm{Hb}$ level was higher in EPO sensitive group compared to the lower $\mathrm{Hb}$ level in EPO resistant group and we 
also found that serum hepcidin level is higher in EPO resistant group compared to the lower levels in EPO sensitive group. Our results showed a significant negative correlation between serum hepcidin level and haemoglobin concentration.

In normal healthy individual, the decrease in $\mathrm{Hb}$ level will have a negative feedback inhibition on hepcidin that will allow more iron to be available for erythropoiesis, But in CKD patient there is an impairment in hepcidin clearance through kidneys that allow hepcidin to build up in blood and cause reticuloendothelial block, decrease iron availability and eventually worsening of anaemia. This may explain the significant negative correlation that we have found in our study.

Our results are in agreement with others $(8,5)$ that found significantly higher hepcidin and lower $\mathrm{Hb}$ levels in EPO resistant haemodialysis patients. This also matched with other studies (9 and 10) which were done on similar sample size like our study.

We found that serum iron level is elevated in EPO sensitive group compared to lower iron level in EPO resistant group. There was a significant negative correlation between serum hepcidin level and serum iron. In agreement with our results, some studies $(9,11)$ showed that there is a significant negative correlation between hepcidin and serum iron. But in contrast to our results, a study found no correlation between serum hepcidin and iron levels (8).

We found that serum ferritin level is higher in EPO sensitive group compared to the lower serum ferritin level in EPO resistant group.

In our study there was a significant negative correlation between serum hepcidin and serum ferritin levels. This may be explained by the higher target of serum ferritin level need to be reached in hemodialysis patient than in normal healthy population and the maintenance intravenous iron given on weekly basis to overcome iron loss during each dialysis session that allow iron availability and suppress hepcidin production in those patients.

Serum ferritin is a marker of iron stores in the liver and reticuloendothelial system (RES) as well as being an acute phase protein, So the high ferritin level in hemodialysis patients couldn't be fully explained by inflammation and need further evaluation.

Our results were in agreement with that study which found a significant negative correlation between serum hepcidin levels and ferritin (11). This was in contrast to 
many other researches in which it was proved that a highly significant positive correlation between serum hepcidin levels and ferritin $(12,9,13 \& 14)$. This may be explained by the higher sample size than our study and that one of those studies (12) was done on haemodialysis patients with chronic hepatitis $\mathrm{C}$ virus. Otherwise, an insignificant positive weak correlation between serum levels of hepcidin and ferritin (15).

The variable study results may be explained by the diurnal variation in serum hepcidin concentration that was not found in ferritin measurement and that the influence of inflammation on hepcidin in hemodialysis patients is not crucial and other factors (eg : hepcidin retention due to renal impairment) are involved.

We found that transferrin saturation is higher in EPO sensitive group compared to the lower saturation in EPO resistant group. There was a significant negative correlation between serum hepcidin level and transferrin saturation. This correlation is due to the blocking effect of hepcidin on reticuloendothelial system that decreases iron availability and therefore decreases transferrin saturation.

Our results are consistent with those of study published in Medicinia 2017 (5), But in contrast that published in Indian Journal of
Nephrology 2017 (16) that found significant positive correlation between serum hepcidin and transferrin saturation. As this study was done in CKD 3-5 non dialysis patients that could be explained by stopping the EPO therapy two weeks before the study, the larger sample size compared to our study and the younger age group chosen for their study. This difference between results in dialysis versus non-dialysis patients can explain the effect of hemodialysis on removal of hepcidin.

We found that CRP titre is higher in EPO resistant group with compared to lower levels in EPO sensitive group. As it is known that hepcidin synthesis is induced by inflammation, so positive correlation between hepcidin and CRP was very expected especially among patients undergoing hemodialysis which is currently being considered as an inflammatory state. However, we found that there is no significant correlation between serum hepcidin and CRP titre in our study.

Our results were in agreement with the study done in 2017 (5) that also found no apparent correlation between CRP and hepcidin. Unlike our study, Ford et al. (17), Rubab et al. (8) and Ibrahim et al. (18) showed that there is a significant positive correlation of hepcidin levels with $\operatorname{CRP}(17,18,8)$. This 
may possibly be due to exclusion of patients with active infection and may be explained on the basis of differences in the half-lives of CRP and hepcidin and the diurnal variation of hepcidin.

We found that all patients in the EPO resistant group required treatment with higher doses of EPO compared to the lower doses required in most of EPO sensitive group. There was a highly significant positive correlation between serum hepcidin level and the weekly dose of EPO in our hemodialysis patients.

This correlation is due to the hepcidin blocking effect on reticuloendothelial system that decrease iron availability and hence decrease erythropoiesis and haemoglobin concentration so patients will require more doses of EPO to suppress the effect of hepcidin.

As erythropoietin (EPO) is the primary signal that triggers erythropoiesis in anaemic and hypoxic conditions, so Pinto et al. (19) studied the effect of erythropoetin dose on hepcidin regulation and reported that EPO has a direct dose-dependent role in the regulation of hepcidin expression.

This is in agreement with the research which reported that the hepcidin levels in hemodialysis patients who received no EPO were lower when compared with the levels in those patients and receiving the maximum dose of EPO (20).

This also matched with the study that was done on haemodialysis patients and showed that the short and long-acting EPO exert biphasic effects on hepcidin in early upregulation followed by late downregulation. An early rise in serum hepcidin in response to EPO may be dependent on serum ferritin and predictive of the response to EPO in hemodialysis patients (21).

But unlike our finding, no significant correlation was found between hepcidin and dose of erythropoietin in hemodialysis patients. (22). While a different research reported that there was a significant negative correlation between serum hepcidin levels and weekly erythropoietin doses (18).

The different study results could be explained by understanding that the dose of erythropoietin is not the only factor that regulate hepcidin level and additional mediators of hepcidin expression in the context of erythropoiesis, has recently been demonstrated for the TGF- $\beta$ super-family member GDF15. And so that a direct signalling of EPO to the hepatocyte could be one of the mechanisms underlying the 
reported in vivo hepcidin modulation by erythropoiesis (19).

We found that serum PTH was higher in EPO sensitive group compared to the lower level in the EPO resistant group. Excessive parathormone levels are known to reduce EPO production, increase haemolysis, and suppress stem cells of the red blood cell line in the bone marrow. As a result it will increase the EPO dose required for those patients that will eventually suppress hepcidin production. (23)

In contrast to that, we found that there is no significant correlation between serum hepcidin level and serum PTH in our haemodialysis patients. This is consistent with others (5 and 18) that proved no possible correlation between serum hepcidin and serum PTH. But unlike our finding, a research was done on non- dialysis patients, found that there is a significant positive correlation between hepcidin and PTH (24).

We also found that serum phosphorous is higher in EPO resistant group compared to lower level in EPO sensitive group. There was a significant positive correlation between serum hepcidin level and serum phosphorous in our hemodialysis patients. This correlation could be due to the effect of decreased renal clearance of both hepcidin and phosphorous. This was in agreement with studies that showed a significant positive correlation between hepcidin and phosphorous level in hemodialysis patients ( $24 \& 25)$.

\section{Conclusion}

Hepcidin is associated with anaemia, markers of iron status and erythropoietin resistance. If used as a diagnostic tool, it might improve iron therapy in patients with functional iron deficiency due to reticuloendothelial blockage of iron transport. This is important to avoid iron overload and to improve erythropoietin (EPO) response in patients with ESRD. In addition to that, these findings may be of great benefit to understand the importance of hepcidin antagonists to treat anaemia in hemodialysis patients.

\section{References}

1. Vaidya SR, Aeddula NR. Chronic Renal Failure. In: StatPearls [Internet]. StatPearls Publishing; 2019.

2. Shaikh H, Aeddula NR. Anemia of chronic renal disease. StatPearls [Internet]. 2020;

3. D'angelo G. Role of hepcidin in the pathophysiology and diagnosis of anemia. Blood Res. 2013;48(1):10-5.

4. Suega K, Widiana GR. Predicting hepcidin level using inflammation markers and iron indicators in patients with anemia of chronic disease. Hematol Transfus cell Ther. 2019;41(4):342-8.

5. Petrulienė K, Žiginskienė E, Kuzminskis V, Nedzelskienė I, Bumblytè IA. Hepcidin serum levels and 
resistance to recombinant human erythropoietin therapy in hemodialysis patients. Medicina (B Aires). 2017;53(2):90-100.

6. Costa E, Swinkels DW, Laarakkers CM, Rocha-Pereira P, Rocha S, Reis F, et al. Hepcidin serum levels and resistance to recombinant human erythropoietin therapy in haemodialysis patients. Acta Haematol. 2009;122(4):226-9.

7. do Sameiro-Faria M, Ribeiro S, Rocha-Pereira P, Fernandes J, Reis F, Bronze-da-Rocha E, et al. Body mass index and resistance to recombinant human erythropoietin therapy in maintenance hemodialysis patients. Ren Fail. 2013;35(10):1392-8.

8. Rubab Z, Amin H, Abbas K, Hussain S, Ullah MI, Mohsin S. Serum hepcidin levels in patients with endstage renal disease on hemodialysis. Saudi J kidney Dis Transplant. 2015;26(1):19.

9. El-HadyAhmed H, Emam El-Maghraby A, El-Hady Ahmed H. EVALUATION OF THE ROLE OF HEPCIDIN IN PREDICTING THE THERAPEUTIC EFFICACY OF ERYTHROPOIESIS-STIMULATING AGENT TREATMENT IN PATIENTS OF CHRONIC RENAL FAILURE. Vol. 22, ZUMJ. 2016.

10. Shinzato T, Abe K, Furusu A, Harada T, Shinzato K, Miyazaki M, et al. Serum pro-hepcidin level and iron homeostasis in Japanese dialysis patients with erythropoietin (EPO)-resistant anemia. Med Sci Monit. 2008 Sep;14(9):CR431-7.

11. Kadery Alkemary A, Elgarem N, Taha Mohamed R, Ismail Aboueleinein B. OF ADVANCED RESEARCH Value of hepcidin in diagnosis and monitoring of iron disorders in patients on regular hemodialysis and its relation to hev infection. Int J Adv Res. 2016;4(7):165162.
12. Al-Amir M, Hassan A, Elshafie S, Zein Elabdin H, Taha S. The relationship between anemia, serum hepcidin levels, and chronic hepatitis $\mathrm{C}$ in chronic hemodialysis patients. Egypt J Intern Med. 2017;29(3):112.

13. Kato A, Tsuji T, Luo J, Sakao Y, Yasuda H, Hishida A. Association of prohepcidin and hepcidin-25 with erythropoietin response and ferritin in hemodialysis patients. Am J Nephrol. 2007 Nov;28(1):115-21.

14. Tomosugi N, Kawabata H, Wakatabe R, Higuchi M, Yamaya $\mathrm{H}$, Umehara $\mathrm{H}$, et al. Detection of serum hepcidin in renal failure and inflammation by using ProteinChip System. Blood. 2006 Aug;108(4):1381-7.

15. Elmenyawi AAI, Hassan A, Said SA. Relationship between Hepcidin, Ferritin and C-Reactive Protein in Hemodialysis Patients. Egypt J Hosp Med. 2017 Oct;69(2):1786-93.

16. Goyal H, Mohanty S, Sharma M, Rani A. Study of anaemia in nondialysis dependent chronic kidney disease with special reference to serum hepcidin. Indian $\mathbf{J}$ Nephrol. 2017 Jan;27(1):44-50.

17. Ford BA, Eby CS, Scott MG, Coyne DW. Intraindividual variability in serum hepcidin precludes its use as a marker of iron status in hemodialysis patients. Kidney Int. 2010 Oct;78(8):769-73.

18. Ibrahim I, Mohamad U, Rashad A, Darweesh H. Impact of hepcidin, interleukin 6, and other inflammatory markers with respect to erythropoietin on anemia in chronic hemodialysis patients. Egypt J Intern Med. 2014;26(1):6.

19. Pinto JP, Ribeiro S, Pontes H, Thowfeequ S, Tosh D, Carvalho F, et al. Erythropoietin mediates hepcidin expression in hepatocytes through EPOR signaling and 
Benha medical journal, vol. 38, issue 2, 2021

regulation of $\mathrm{C} / \mathrm{EBP} \alpha$. Blood. 2008 Jun;111(12):572733.

20. Zumrutdal A, Sezgin N. The relationship between anemia, liver disease, and hepcidin levels in hemodialysis patients with hepatitis. Indian J Nephrol. 2012;22(6):415.

21. Takasawa K, Tomosugi N, Takaeda C, Maeda T, Ueda N. Regulation of Hepcidin-25 by Short- and LongActing rhEPO May Be Dependent on Ferritin and Predict the Response to rhEPO in Hemodialysis Patients. Nephron Extra. 2014 Apr;4(1):55-63.

22. Afifi WM, Mostafa E, Elsaid M, Elakad G, Ebian HF. Serum hepcidin levels and erythropoietin resistance in hemodialysis patients. J Egypt Soc Nephrol Transplant. 2019;19(1):13.
23. Tanaka M, Komaba H, Fukagawa M. Emerging Association Between Parathyroid Hormone and Anemia in Hemodialysis Patients. Vol. 22, Therapeutic Apheresis and Dialysis. Blackwell Publishing Ltd; 2018. p. $242-5$.

24. Hyang Ki Min, Su Ah Sung YKO et al. Hepcidin, iron indices and bone mineral metabolism in non-dialysis chronic kidney disease | Nephrology Dialysis Transplantation | Oxford Academic. Oxford University Press. 2018. p. 147-154.

25. Zaritsky J, Young B, Gales B, Wang HJ, Rastogi A, Westerman M, et al. Reduction of serum hepcidin by hemodialysis in pediatric and adult patients. Clin $\mathbf{J}$ Am Soc Nephrol. 2010 Jun;5(6):1010-4.

To cite this article: Ayman M. Elbadawy, W. M. Ibraheim, Medhat A. Khalil, Omar N. Elhawary, Rasha O. Abdelmoniem. Study of Serum Hepcidin Level and its Relation to Recombinant Human Erythropoietin Resistance, Markers of Iron Status and C-reactive Protein in Patients with End Stage Renal Disease on Maintenance Haemodialysis. BMFJ 2021; 38(2): 497-510. DOI: 10.21608/bmfj.2021.66540.1391 